This is a post-print (i.e. final draft post-refereeing) of a manuscript submitted to Journal of the Operational Research Society.

To cite this article: Santos, S.P., Amado, C.A.F. and J.R. Rosado (2011). "Formative evaluation of electricity distribution utilities using Data Envelopment Analysis". Journal of the Operational Research Society, 62(7): 1298-1319.

To link to this article: http://dx.doi.org/10.1057/jors.2010.66

\title{
Formative Evaluation of Electricity Distribution Utilities Using Data Envelopment Analysis
}

Sérgio P. Santos ${ }^{a,}{ }^{*}$, Carla A.F. Amado ${ }^{a}$, and Joaquim R. Rosado ${ }^{b}$

${ }^{a}$ Centre for Advanced Studies in Economics and Econometrics Faculty of Economics, University of Algarve, 8005-139 Faro, Portugal Email: ssantos@ualq.pt; camado@ualq.pt

\author{
${ }^{b}$ EDP Distribuição, S.A., Estrada da Penha, 8000-116 Faro, Portugal \\ Email: JoaquimRosa.Rosado@edp.pt
}

${ }^{*}$ Corresponding author:

Faculty of Economics

University of Algarve

Campus de Gambelas, Edifício 9

8005-139 Faro

Portugal

E-mail: ssantos@ualg.pt

Tel: 00351289817571

Fax: 00351289800064 
Abstract - The use of Data Envelopment Analysis (DEA) in the electricity distribution sector has been prolific in the number of papers published in research journals. However, while numerous studies have been documented, they have mostly been summative. Their aim has been predominantly descriptive and classificatory. This paper argues that evaluations of a formative nature are more effective than summative studies in promoting a better understanding of the structures and processes of electricity distribution utilities and, consequently, are more appropriate to contribute to performance improvement. To illustrate the use of DEA for formative evaluation, and highlight some of the difficulties of using DEA in practice, this paper compares the cost-efficiency of the Portuguese electricity distribution companies from 2002 to 2006. A dynamic analysis using Malmquist Indices is also conducted in order to evaluate the changes in productivity over this period. Our analysis shows that the application of DEA for formative purposes meets some difficulties. In particular it shows that whilst the modelling of productivity/efficiency scores using DEA is relatively straightforward, it is comparatively more difficult to develop models that are economically valid and that produce results with face validity. Based on the insights derived from this analysis the paper provides some recommendations regarding the successful application of DEA for performance improvement.

Keywords — Data envelopment analysis, electricity distribution, performance measurement. 


\section{Introduction}

The electricity energy sector worldwide has undergone major reforms in the last two decades in an attempt to promote efficiency and productivity gains. This has been particularly evident in electricity distribution. The supply of electricity is, in many countries, considered a public service and it has to be delivered with adequate standards of quality and in an efficient and productive manner.

While efficiency and productivity in electricity generation are, to a large extent, determined by technological factors, in the electricity distribution sector they are mainly determined by management and efficient labour use (Kumbhakar and Hjalmarsson, 1998). Furthermore, it is important to bear in mind that electricity retail distribution has a much closer relationship with customers than electricity generation. Therefore, an appropriate measurement and management of the performance of the distribution utilities can play an important role in ensuring an efficient and effective use of their resources and so help the delivery of high quality services to the customers.

One method to measure performance is to benchmark an electricity distribution utility against others performing similar activities. A benchmarking exercise allows the distribution utilities to compare themselves with the best-observed practices in the sector and then to develop plans of action for improving their performance. A good benchmarking exercise should allow the distribution utilities to learn about how other utilities are able to do better. However, the challenge is to identify 'best practices', as what constitutes 'best practice' is in itself dependent upon the perspective taken and dependent upon the priorities of the distribution utility under evaluation. Therefore, what constitutes 'best practice' to one organisation might not constitute 'best practice' to another.

Data envelopment analysis (DEA) (Charnes et al, 1978) is a non-parametric linear programming technique which has proved very effective in determining best practices and it has been extensively used for benchmarking. DEA has been used to evaluate efficiency of different types of decision making units (DMU) including banks, hospitals, universities, courts of law and also electricity utilities. However, while several single and multi-country studies of relative efficiency of electricity distribution utilities have been reported, these studies have tended to be of a summative rather than formative nature.

Scriven (1967) distinguishes between two types of evaluation, depending on its objectives and on the types of methods used, summative evaluation and formative evaluation. Summative evaluation involves the collection and analysis of data with the aim of determining whether a programme should be continued or stopped and whether an organisation is performing better or worse than another. In contrast, formative evaluation involves the collection and analysis of data with the aim of developing and improving the programme or the organisations. Formative evaluation studies are characterised by an effort to involve the stakeholders and to provide useful feedback to the decision makers and policy makers in terms of organisational improvement and knowledge development.

On the basis of these definitions, a careful analysis of the literature allows us to realise that whilst numerous studies have been documented on the use of DEA in the electricity distribution sector, they have been mostly summative; that is, their aim has been predominantly descriptive 
and classificatory. As pointed out by Lins et al (2007) one serious drawback of several DEA applications in this area has been the absence of decision making judgement, which can lead to unrealistic results from the firms' perspective.

In contrast, the evaluation we discuss in this paper is predominantly formative, characterised by an effort to involve decision makers and to provide useful information for organisational management and improvement. Its ultimate aim is the promotion of learning.

In consistency with previous publications (e.g. Wholey, 1996), this paper argues that evaluations of a formative nature in the electricity distribution industry, involving the decision makers, are more effective than summative evaluation studies. They promote a better understanding of the structures and processes of electricity distribution utilities and, consequently, are more appropriate to contribute for performance improvement. To illustrate the use of DEA for formative evaluation, this paper compares the cost-efficiency of the Portuguese electricity distribution companies over the period 2002 to 2006. A Malmquist index (Malmquist, 1953; Caves et al, 1982; Färe et al, 1994) and its components, shift in frontier technology and change in efficiency, are also calculated for this period.

This study makes a contribution to the DEA literature on two grounds. Firstly, it provides one of the most exhaustive accounts of the use of DEA in the electricity distribution sector. Secondly, it discusses the interactive development of a DEA model for formative evaluation, highlights some of the difficulties of using DEA in practice and provides some guidance regarding the successful application of DEA for formative purposes.

The remainder of this paper is organised as follows. Section 2 comments on the extent to which the use of DEA in the electricity distribution area is reflected in the literature. Section 3 details the empirical study and discusses its main results. In particular, it discusses the process and outcomes of developing a DEA model involving key stakeholders of the organisation under study and aimed at providing useful feedback to the decision makers in terms of organisational improvement. Section 4 concludes with some closing remarks and an outline of the ongoing research agenda. A comprehensive review of the DEA technique, including the Malmquist Productivity Index, can be found in Boussofiane et al (1991), Cooper et al (2000) and Cooper et al (2004).

\section{Literature review}

The use of DEA in the electricity power industry sector is not new. Indeed, since the early-1980s, DEA has been used increasingly to measure the relative performance of electricity utilities. One of the pioneering works on the use of DEA in this area is that of Färe et al (1983). The authors used DEA to evaluate the relative efficiency of Illinois electricity utilities. Since then, several studies have applied DEA to the measurement of performance in each of the four functions of the electricity sector (production, transmission, distribution and retail). This paper, however, is only concerned with the distribution function, which consists of the transfer of electricity from the transport systems to the final client (domestic, industrial, and commercial consumers) by means of a distribution network. 
The relative efficiency of electricity distribution utilities has attracted considerable interest worldwide in the last decade due to the restructuring of the electricity energy sector, particularly with the introduction of regulation, privatisation and trade liberalisation in several countries. For a recent survey on the use of DEA by regulators in several countries to evaluate relative performance of electricity distribution companies in the process of rate regulation, the reader is referred to Haney and Pollitt (2009). This interest has led to the publication of several single country and intercountry studies on this matter.

\subsection{Single-country studies}

As with the study of Färe et al (1983) mentioned above, Charnes et al (1989), Pahwa et al (2002) and Tsutsui and Goto (2009) also used DEA to evaluate the efficiency of electricity utilities in the United States. Their work, however, used more complex DEA models. Several other authors have also contributed to this body of literature. For example, Weyman-Jones initially in 1991 (WeymanJones, 1991) and later in 1995 (Weyman-Jones, 1995) explored the use of DEA to compare the efficiencies of 12 distribution companies in England and Wales before and after their privatisation in 1990.

Other studies using DEA to evaluate the efficiency of electricity distributors in the United Kingdom (UK) include Giannakis et al (2005) and Yu et al (2009). The former study used DEA to examine the desirability of incorporating service quality into incentive regulation of electricity networks, having found some evidence of trade-offs between cost and quality. The later study used DEA to examine the effect of a set of weather factors on the cost and quality performance of the electricity distribution networks, having found that such factors often do not have a significant effect on the overall performance of utilities.

Miliotis (1992) used DEA to evaluate the efficiency of 45 electricity distribution districts of the Greek Public Power Corporation, having adopted a slightly different approach in his analysis. He used different DEA models in order to explore the effects of geographic region, size and grid sparsity on the results, concluding that big urban centres had higher efficiencies than sparse population regions. Chen (2002) and Yang and Lu (2006) reporting on studies of the electricity distribution sector in Taiwan also concluded that the average technical efficiency score of urban distributors was considerably higher than that of rural distributors, due to the geographical dispersion of the consumers of the latter one. Given that urban concentration may affect efficiency, it is recommended that separate DEA analyses should be carried out for urban distributor and rural distributor groups, respectively, or that a variable relating to the geographical dispersion of customers should be included in the DEA model.

Hjalmarsson and Veiderpass (1992) examined the productivity growth effect in electricity retail distribution in Sweden during the period from 1970 to 1986, also through a DEA framework, with productivity being measured by means of the Malmquist index. The study showed that productivity increased substantially over an extended period of time, that productivity growth of rural areas exceeded the growth in urban areas, and that productivity change was independent of ownership.

The impact of ownership on the efficiency of distribution utilities has, however, resulted in 
different conclusions. While Hjalmarsson and Veiderpass (1992) and Pollitt (1995) found that publicly owned and privately owned electricity distribution utilities exhibit no significant difference in efficiency, Bagdadioglu et al (1996) reporting on a study of the Turkish electricity distribution sector, and Kumbhahar and Hjalmarsson (1998) reporting on a study of the Swedish electricity distribution sector found that the privately owned companies operated more efficiently.

On a similar line of research, some studies have also been carried out in order to assess whether changes in the firms' ownership impacted on their performance. Pérez-Reyes and Tovar (2009), for example, have found evidence that the market restructuring and consequent privatisation of the 14 Peruvian electricity distribution companies have brought about improvements in the efficiency and productivity of the sector. The reforms experienced in the electricity distribution sector worldwide in the last decade, have had, however, different impacts across countries. Ramos-Real et al (2009), for example, in assessing the evolution and main determinants of productivity in the Brazilian electricity distribution sector, found evidence that the reforms in the regulation implemented in the 1990s, which resulted in the privatisation of most of the firms, do not seem to have led these to behave in a more efficient manner. The poor performance of a considerable number of Brazilian distribution companies had already been previously identified by Resende (2002). Other studies in other countries, have found mixed results. Cullmann and von Hirschhausen (2008a), for example, analysed the impact of market restructuring on the performance of the Polish electricity distribution sector and found that whilst technical efficiency increased, allocative efficiency deteriorated during the transition towards a market economy. They also found evidence that the smaller companies were on average less efficient, largely due to scale inefficiency suggesting that the regulatory authority should allow companies to merge into larger units.

The right scale of operations is an issue which has also attracted considerable interest. Indeed, some studies have found evidence that scale plays a major role in the efficiency of the sector. Thakur et al (2006), for example, reporting on a study of the Indian electricity distribution sector, found evidence that part of its inefficiency is due to the large size of the distribution companies, suggesting that restructuring and downsizing the operations may help utilities to improve their performance. Arocena (2008) also found evidence of potential scale gains by dividing the largest Spanish utilities into smaller units. These findings clearly contrast with the ones of Cullmann and von Hirschhausen (2008a) reported above, which suggested that the merging of operations on the Polish electricity distribution sector could lead to efficiency improvements. There are studies, however, that found evidence that the scale of operations only plays a minor role on the performance of the companies. A good example is the work carried out by von Hirschhausen et al (2006) on the German electricity distribution companies.

Other countries where DEA has been used to evaluate the efficiency of distribution utilities include Norway (Førsund and Kittelsen, 1998; Agrell et al, 2005), Philippines (Pacudan and de Guzman, 2002), Finland (Korhonen and Syrjänen, 2003), Chile (Sanhueza et al, 2004), Colombia (Pombo and Taborda, 2006), Iran (Azadeh et al, 2009a,b), Ukraine (Berg et al, 2005) and Portugal (Weyman-Jones et al, 2004, 2008). It is important to emphasise, however, that whilst some studies 
exist exploring the use of DEA for the evaluation of electricity distribution utilities in Portugal, they are very rare. The only exceptions we are aware of include the two works mentioned above. In the former, the authors applied a slack based measurement of efficiency to the 14 electricity distributors operating in Portugal and compared the results with those from the 'standard' radial efficiency models. In the later, the authors used several DEA models to examine data on maintenance and outage repair in the Portuguese electricity distribution system during 2004-2005 and draw some lessons about how performance measurement can be implemented within a company, in contrast to the usual public regulatory benchmarking. The results of these studies provide very valuable insights for management purposes. However, because our study discusses the difficulties faced during the modelling process and the means used to address them, it provides useful recommendations regarding the successful application of DEA for performance improvement in practice. It also complements the previous two studies as we explore the effects of scale economies and productivity changes in the sector over time.

\subsection{Inter-country studies}

In addition to the single country studies, some inter-country comparisons have also taken place in recent years. For example, Hattori et al (2005) have examined the relative performance of electricity distribution systems in the UK and Japan between 1985 and 1998 and found that the productivity gain in UK electricity distribution has been larger than in the Japanese sector. Cullmann and von Hirschhausen (2008b), have compared the efficiency of electricity distribution companies in the East European transition countries of Poland, the Czech Republic, Slovakia and Hungary, and found that privatisation has had a positive effect on the technical efficiency in these four countries. They also found that the Czech Republic distribution utilities were the best performers, whilst the Polish were the worse performers. Estache et al (2008) compared, in turn, the efficiency levels and productivity evolution of electricity distribution systems on 12 Southern African countries between 1998 and 2005 having found fairly comparable levels of efficiency in the region. They also found that although the companies have not made significant improvements during the period of analysis in using their capital and human assets, they have done much better in adopting better technologies and better commercial practices.

One of the first studies reporting comparative results across countries was, however, the study carried out by Pollitt (1995). He reviewed efficiency studies carried out in Australia, Canada, Denmark, Germany, Greece, Hong Kong, Ireland, Japan, New Zealand, South Africa, Thailand, Taiwan, UK and United States. Based on the results of the study he concluded that public sector companies performed at least as well as private sector companies.

Other studies also offering insightful discussions on the use of DEA to inter-country benchmarking of electricity distribution utilities include Pardina et al (1998), Edvardsen and Førsund (2003), Jamasb and Pollitt (2003), and Estache et al (2004).

However, it is important to mention that some caution needs to be exercised when analysing the results of inter-country comparisons. As shown by Zhang and Bartels (1998), who examined the effect of sample size on the DEA estimates of efficiency, as sample size increases the 
estimated mean technical efficiencies decrease generally. Therefore, whenever there are significant differences between the samples of distribution utilities belonging to each country, it is recommended that the efficiency scores of all DMUs are obtained from a common frontier and then averaged for each country.

This review of the literature allows us to conclude that the use of DEA in the electricity distribution sector has been prolific in the number of articles published. Whilst most of the studies reviewed in the last two sections report findings which aim to have policy implications, there have been also some studies which have used the electricity distribution sector mainly to illustrate new developments in the use of DEA as an efficiency assessment tool (e.g. Tanure et al, 2006; Sadjadi and Omrani, 2008; Azadeh et al, 2009a, 2009b). Table A in Appendix presents a summary of the studies that have used DEA to compare the efficiency of electricity distribution utilities and which have been published in journals indexed in the Web of Science or EBSCOhost databases. However, while numerous studies have been documented, they have been mostly summative and decision making judgement has been absent from several of these studies (Lins et al, 2007).

In contrast, the evaluation we discuss in the next section is predominantly formative. It intends to promote learning regarding the cost-efficiency and productivity of the electricity distribution utilities in Portugal. Furthermore, by engaging the decision makers in the process of model development and in the interpretation of results, our study highlights some of the difficulties of using DEA in practice.

\section{Empirical analysis}

The Portuguese electricity system has undergone a major transformation in recent years due to its integration in to the liberalised Iberian market and its organisation is based on the co-existence of a Public Electricity System (PES) and an Independent Electricity System (IES), both belonging to the National Electricity System. This paper focuses on the performance evaluation of the distribution utilities belonging to the PES, which is the system responsible for ensuring the supply of electricity in Portugal. The activities developed within the scope of the PES are a public service and have to be delivered with adequate standards of quality and in an efficient and productive manner.

The choice of appropriate input and output variables is a fundamental step in DEA analysis. Based on a review of 20 benchmarking studies of electricity distribution utilities Jamasb and Pollitt (2003) outlined the most widely used input and output variables in this context. It is important to mention, however, that there is no consensus on which variables best describe the operation of distribution utilities.

Some common inputs for electricity distribution models include staff (e.g. number of employees), assets (e.g. network length and transformer capacity) and expenses (e.g. operation and maintenance expenses). The most widely used outputs in literature include units of energy delivered and number of customers.

Although there is no agreement on which factors are controllable and which are not, it is common to use non-controllable inputs (e.g. customer density, climatic conditions) and noncontrollable outputs (e.g. service area) in DEA models to assure comparable technologies. 


\subsection{The DEA model}

The DEA model we discuss bellow, which we have used to assess the efficiency of the 14 electricity distributors operating in Portugal, was developed based on the literature review, statistical analysis of data and based on informal and formal discussions with a group of experts from the Portuguese electricity sector. These discussions resulted from several meetings with the director of one of the distribution utilities assessed and other professionals from the company. The DEA model has assumed an input-orientation, a constant returns to scale (CRS) technology, and two weight restrictions:

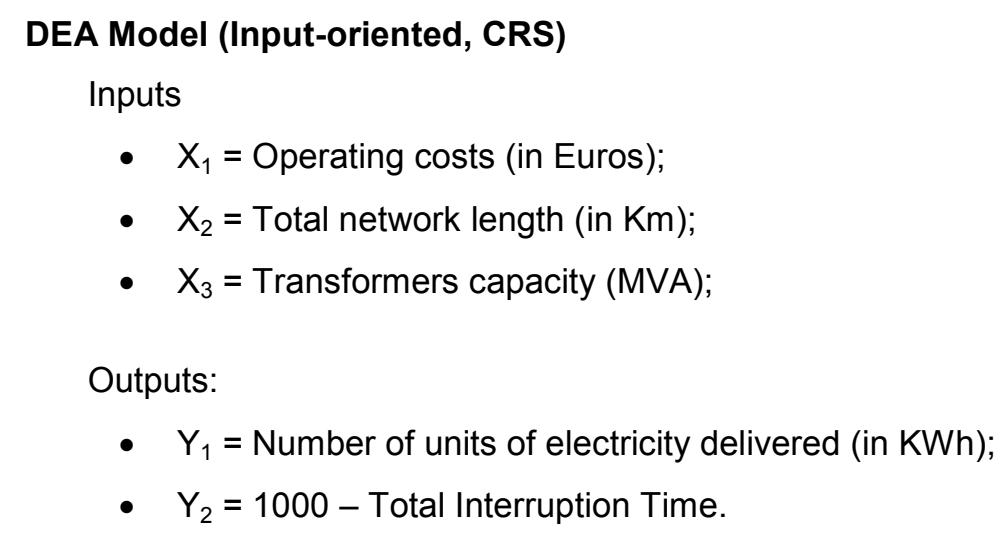

Weight restrictions:

(1) $40 w_{1}-v_{1} \leq 0$;

(2) $w_{2}-84000 v_{1} \leq 0$.

The first input chosen, the operating costs (OPEX), measures the controllable costs of each distribution utility. The costs of electricity distribution are normally broken down in capital costs and operating costs which include maintenance costs. In the present study, the length of distribution lines and the total capacity of the transformers were used as proxies for capital stocks. These inputs were not considered as environmental factors as there was evidence in the data that the distribution companies can control them, even in the short term. Regarding the operating costs, these were selected because they provide a more reliable measure of input use than the number of employees or labour costs as some distributors outsource some of their services.

Regarding the outputs, the number of units of energy delivered was considered as the main cost driver by the experts participating in our study, an opinion which corroborates the findings of Jamasb and Pollitt (2003). Finally it was decided to include as an output an indicator of service quality, measuring the continuity of the supply to the customers. The inclusion of quality indicators in the benchmarking studies of electricity distributions has been sparse. Giannakis et al (2005) are an exception and point out the importance of taking into account the quality dimension in these studies. The total interruption time (in minutes) was found to be the best available indicator for quality. This is, however, an undesirable output, as the objective is to minimise the total interruption time. In order to ensure an isotonic result, we decided to subtract the value of the undesirable 
variable from a large number. Considering that the maximum total interruption time over the 5-year period was 932 minutes, we subtracted the interruption time of each DMU from 1000 minutes. This is in accordance with the suggestion of Dyson et al (2001).

Although the group of experts has recognised that some of the distributors operate in regions with specific territorial characteristics, these were considered not to be important enough to impact on the efficiency of the companies. Consequently, a variable capturing the territorial characteristics was not included in the analysis.

Regarding the restrictions, the first restriction means that if the operating costs increase by one euro, the DMUs should be able to deliver at least 40 more KWh of electricity. The second restriction means that if the operating costs increase by 84000 euros, the DMUs should be able to decrease the total interruption time by at least one minute. This means that $Y_{2}$ should, therefore, increase by at least one.

It is important to mention that this model and the results it produced, which we discuss in the next section, were the outcomes of an interactive process which lasted over two years, and of a critical reflection by the authors and by the group of experts of the Portuguese electricity distribution system that participated in the study. The involvement of some of the key stakeholders on the process, including the director and deputy director of one of the distribution utilities assessed, was aimed to establish the face validity of the results, that is, the extent to which the professionals being evaluated can agree on the appropriateness of the results. As a consequence of the approach adopted, the model above is a refinement of previous versions which had been found unacceptable by the experts. In what follows, we discuss in detail some of the refinements that had to be made, explain the reasons why these had to be made and document on some of the lessons learnt during the process.

First, the approach we have adopted showed that an appropriate specification of the DEA models might play a key role in the acceptance and implementation of the results obtained. This might imply the exclusion of variables initially deemed to be relevant for the analysis, as we explain below, or a careful consideration about the protocol to use in addressing some of the DEA pitfalls, as we discuss in what follows. Although all the variables used in a previous version of the model had been previously agreed by the participants, the use of the total interruption time as an input in this model caused some discomfort within the group. Although quality indicators should be regarded as outputs, considering that in this case the objective is to minimise the total interruption time and that no universal protocol exists to deal with undesirable outputs, technically it was initially used in the DEA model as an input, as suggested by Dyson et al (2001). The reaction of the experts to this action, suggests, however, that the choice of a protocol to address this issue can be relevant. Indeed, it might determine the acceptability, or not, of the results by the decision makers. It was then decided that the total interruption time should be considered as an output.

Second, it showed that in DEA models with a low number of DMUs it might be necessary to use weight restrictions, or other procedures, to ensure both more discrimination in the results and more useful information for decision makers. Although the results achieved by some DMUs in a previous version of the DEA model were in accordance with the expectations of the experts that 
participated in our study, the results of other DMUs were considered clearly unreasonable and unrealistic. In exploring the reasons why the DMUs perceived as inefficient were shown as efficient, it became evident that it was due to the structure of the weights chosen, with many DMUs excluding from the efficiency scores several inputs and/or several outputs, by assigning them a 'zero' weight. The fact that the results presented so many 'zeros' among the optimal weights was considered unacceptable by the decision makers. In particular, the participants in the study mentioned that the OPEX is clearly the most important of the three inputs and the one over which the distribution areas exercise a higher degree of control. Therefore, they emphasised that it would be inappropriate for the areas to ignore this variable in the efficiency analysis, as happened with half of the DMUs in a previous DEA model.

While it was agreed by the participants that some flexibility should be allowed in the choice of weights, they argued that this flexibility should be limited within pre-specified intervals based on the perceived importance of each variable. A proper definition of lower and upper bounds for each interval would prevent some weights from assuming a zero value.

Even with the DMUs perceived as being the best performers, the group was not comfortable with some of the weight structures chosen or with the $100 \%$ efficiency scores achieved by some DMUs. Although it has been recognised by the group that some DMUs clearly perform better than others, the decision makers emphasised that even the best performers have scope for improvement. This suggests that the decision makers use global rather than local scales to compare the distribution areas. Thus, it became apparent during the study that they seem to compare the different units in absolute rather than relative terms.

The low discrimination provided by the initial model, with seven out of 14 DMUs being considered as efficient, was anticipated by the authors and can be partly attributed to the relatively large number of inputs and outputs in comparison with the number of units under assessment. While reducing the number of variables could improve discrimination, this was not considered a good solution on its own as all the variables were considered important by the group to carry out a comprehensive assessment of the electricity distribution units. The only exception to this was the variable 'number of customers', which we had as an output in a previous version of the DEA model, and which the participants in the study considered less informative and relevant than the variable 'units of energy delivered'. Indeed, it was emphasised that the ultimate goal of the distribution utilities is to increase the units of energy delivered and not necessarily the number of customers served. Considering the views of the participants and the high correlation between the two variables (around 91\%), we decided to exclude the variable 'number of customers' from the model. Nevertheless, it may be argued that the number of customers served is an important output to assess the efficiency of public services provision.

There was another variable that made part of the structure of a previous version of the DEA model but that the group decided to exclude from the final version. It was the variable 'service area', which we had as a non-discretionary output to account for factors that might impact on the performance of the utilities but that are beyond their control. The service area is a good indicator for the geographical dispersion of customers. Three reasons have led to the exclusion of this 
variable. The first reason was the fact that in spite of the weight restrictions imposed on the model, some DMUs were still giving all the weight to this output, which is non-controllable, excluding from the efficiency scores the other outputs. This was considered unacceptable by the experts. The second reason was the fact that whilst we could impose further weight restrictions in order to force the model to identify alternative optimal weights, because the variable 'service area' is noncontrollable, production trade-offs involving this variable were considered inappropriate. The third reason was the fact that while the experts agreed that the service area of some DMUs could partly influence their operating costs, they emphasised that in the Portuguese context the geographical dispersion of customers between the different DMUs is not a major factor impacting on their efficiency.

In order to further improve discrimination amongst DMUs and to obtain a more reasonable weight structure, we decided therefore to exclude the variables 'number of customers' and 'service area', and to include the two weight restrictions previously described. The need to address this issue was critical for two reasons. Firstly, it was the only way to ensure that the results would be acceptable to and accepted by the decision makers. Secondly, during the research it became apparent that it could be important to explore the impact of scale economies in the efficiencies of the different distribution areas. Considering that a variable returns to scale (VRS) model will always envelop the data more closely than a CRS model, if no weight restrictions were to be imposed, the discrimination would be even poorer than the one obtained with previous versions of the DEA model. It is important to emphasise, however, that the use of weight restrictions is just one of several methods that can be used to achieve more discrimination when the number of DMUs is low. On the next section we discuss the use of the slacks based measurement (SBM) of efficiency, as proposed by Tone (2001).

Third, the modelling process revealed that defining weight restrictions may prove more difficult than anticipated. Although the use of production trade-offs would improve the discrimination of the results and at the same time preserve the traditional meaning of efficiency as a radial improvement factor for inputs or outputs (Podinovski, 2004, 2005, 2006), the decision makers showed considerable resistance regarding the definition of these trade-offs. They were able to easily express the perceived importance of the different inputs and outputs, but were reluctant to express their views regarding possible trade-offs.

Considering that efficiency measures lose their technological meaning when weight restrictions based on the perceived importance of the variables are used (Allen et al, 1997), we defined production trade-offs based on the analysis of the available data and on our knowledge regarding the workings of the Portuguese electricity sector. These trade-offs were then discussed with and revised by some of the experts that participated in the study.

\subsection{The efficiency results and testing for the existence of scale economies}

The data analysis was initially carried out for the most recent year of operation (2006) and an inputoriented model was used. As pointed out by Jamasb and Pollitt (2003) an input-oriented specification is commonly regarded as the most appropriate form for electricity distribution utilities, 
as demand for distribution services is a derived demand that is beyond the control of utilities and has to be met. It is important to emphasise, however, that the degree of control of the distribution utilities over some of these inputs is limited. For example, the group of experts participating in the study mentioned that while the network length and the transformers capacity can be reduced, this is very unlikely to happen. This fact imposes some restrictions regarding the implementation of some of the targets suggested by the DEA analysis as these targets might not be realistically achievable.

Table 1 presents the results from the DEA Model. It presents the efficiency scores for each one of the 14 distributors operating in Portugal during 2006 as well as the virtual inputs $\left(v_{1} x_{1 \mathrm{~s}}+\ldots+\right.$ $\left.v_{3} x_{3 s}\right)$ and virtual outputs $\left(w_{1} y_{1 s}+\ldots+w_{3} y_{3 s}\right)$ for each DMU.

TABle 1 - Efficiency Scores ANd ViRtual InPUts/OutPuts for Portuguese EleCtRicity DistRibution IN 2006

\begin{tabular}{ccccccc}
\hline DMUs & Efficiency (\%) & $\begin{array}{c}\text { Virtual Input 1 } \\
\boldsymbol{V}_{\mathbf{1}} \boldsymbol{X}_{\mathbf{1 s}}\end{array}$ & $\begin{array}{c}\text { Virtual Input 2 } \\
\boldsymbol{V}_{\mathbf{2}} \boldsymbol{X}_{\mathbf{2 s}}\end{array}$ & $\begin{array}{c}\text { Virtual Input 3 } \\
\boldsymbol{V}_{\mathbf{3}} \boldsymbol{X}_{\mathbf{3 s}}\end{array}$ & $\begin{array}{c}\text { Virtual Output 1 } \\
\boldsymbol{W}_{\mathbf{1}} \boldsymbol{y}_{\mathbf{1 s}}\end{array}$ & $\begin{array}{c}\text { Virtual Output 2 } \\
\boldsymbol{W}_{\mathbf{2}} \boldsymbol{y}_{\mathbf{2 s}}\end{array}$ \\
\hline 1 & $77.12 \%$ & 0.30 & 0.00 & 0.70 & 0.58 & 0.42 \\
2 & $85.37 \%$ & 0.46 & 0.54 & 0.00 & 0.99 & 0.01 \\
3 & $76.30 \%$ & 0.43 & 0.00 & 0.57 & 0.28 & 0.72 \\
4 & $96.77 \%$ & 0.60 & 0.00 & 0.40 & 0.00 & 1.00 \\
5 & $100.00 \%$ & 0.85 & 0.00 & 0.15 & 0.00 & 1.00 \\
6 & $89.81 \%$ & 0.48 & 0.00 & 0.52 & 1.00 & 0.00 \\
7 & $93.45 \%$ & 0.35 & 0.00 & 0.65 & 0.55 & 0.45 \\
8 & $85.38 \%$ & 0.29 & 0.00 & 0.71 & 0.55 & 0.45 \\
9 & $82.27 \%$ & 0.52 & 0.00 & 0.48 & 0.23 & 0.77 \\
10 & $90.49 \%$ & 1.00 & 0.00 & 0.00 & 0.00 & 1.00 \\
11 & $100.00 \%$ & 0.43 & 0.57 & 0.00 & 1.00 & 0.00 \\
12 & $86.45 \%$ & 0.59 & 0.41 & 0.00 & 0.00 & 1.00 \\
13 & $100.00 \%$ & 0.62 & 0.00 & 0.38 & 0.80 & 0.20 \\
14 & $67.74 \%$ & 0.45 & 0.00 & 0.55 & 0.30 & 0.70 \\
\hline
\end{tabular}

Note: $y_{i s}$ is the amount of output $i$ generated by unit $s ; x_{i s}$ is the amount of input $j$ used by unit $s ; w_{i}$ is the weight associated with output $i ; v_{j}$ is the weight associated with input $j$.

It is important to emphasise that the DEA model presented in this section was discussed in a workshop attended by six members of the company, including the director of one of the distribution utilities assessed, and it was considered the most consensual one. It is the model with the most discriminating power and the one with the weight structure that most closely reflects the views of the experts that participated in the process. The fact that the efficiency scores produced by this model were considered far more realistic than the ones produced by the previous versions, and that the weight structures were now considered more meaningful, were very important factors to give credibility and legitimacy to the results obtained. The information about the 'peers' also played a relevant role in this regard. For example, DMU 13 is clearly perceived as one of the most efficient units and regarded as a model for other units. This perception of the participants was confirmed by the DEA results as DMU 13 is shown as a peer to all but one of the inefficient DMUs. However, the fact that DMU 5 appeared as efficient caused initially surprise to some of the participants. This 
surprise soon eased when they became aware that the inefficient units that use DMU 5 as peer have identical structures to this unit but are perceived as less efficient.

Given that this model was consensual and that it was considered by all the experts participating in the process as the most appropriate to carry out a fair comparison in the sector, we decided to run it with the cross-section data for each of the five years under analysis (2002-2006), in order to compute the relative efficiency scores of each DMU. We also decided to analyse the changes in productivity over time. For that, and following Tone (2004), we calculated the Malmquist Productivity Indexes (MPIs) for the years of 2002-2003, 2003-2004, 2004-2005, 2005-2006 and lastly, a global index for the interval of 2002-2006. It is important to mention that operating costs were measured at fixed prices of 2002, using general price deflators from the Portuguese National Institute of Statistics.

Table 2 presents some of the results obtained. The results from our analysis suggest that, on average, productivity has changed considerably over the 5 -year period. On average, the results suggest that for the period of 2002-2006, the sector benefited from gains in productivity of around $11 \%$. These gains can be broken down into $14 \%$ improvement in the frontier (innovation) and $2 \%$ decrease in companies' efficiency (the distance of each unit to its respective frontier). A closer inspection of the results allows us to verify, however, that most of the gains in productivity were achieved in the early years of the period under consideration. Furthermore, not all of the DMUs contributed to these gains. For example, distribution unit 9 shows over the five-year period gains in productivity of around $34 \%$. This unit has both benefited from moving nearer to the respective annual frontier (15\% improvement) and from progress in the frontier technology $(17 \%$ improvement). In contrast, the MPI of distribution unit 3 shows that there were basically no changes in productivity from 2002 to 2006 . However, the break down of the index into its two components shows that the frontier technology around this unit improved significantly (20\% progress), but the unit was unable to 'keep up' with the pace, showing a significant decrease in efficiency over the five-year period.

TABle 2 - MalmQuist Productivity Growth Rates And Decomposition From 2002 to 2006

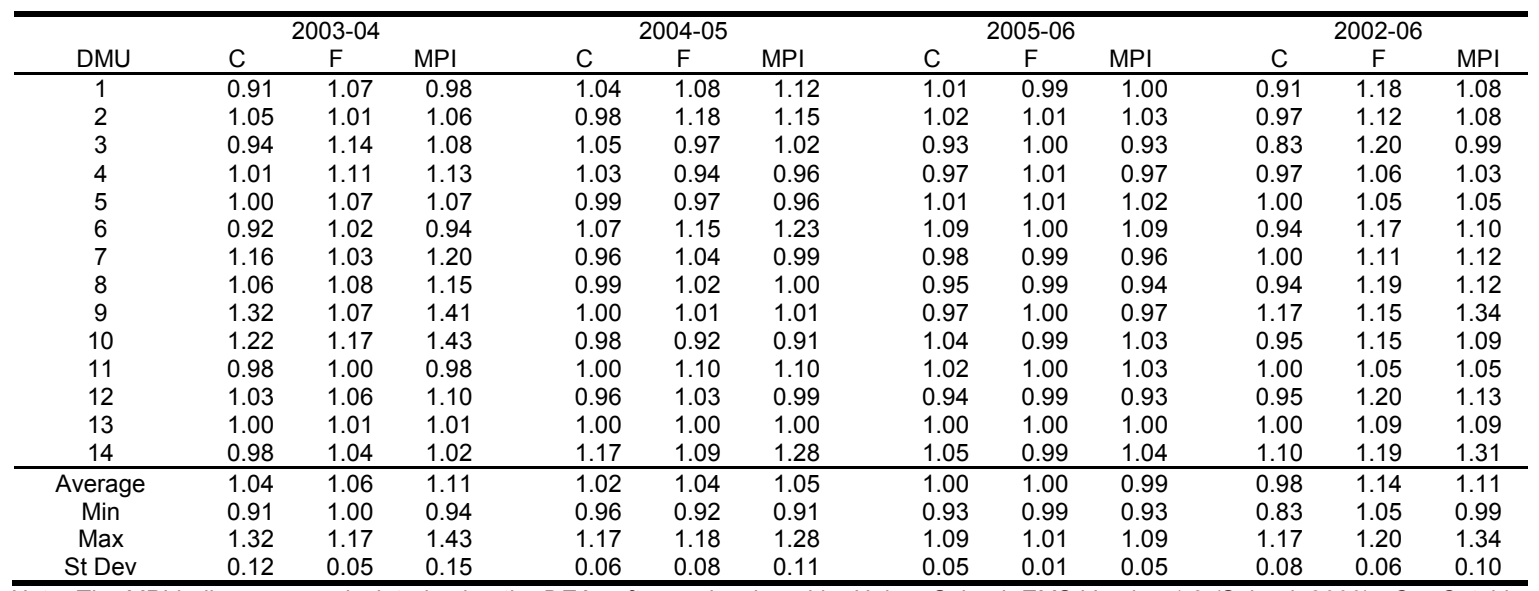

Note: The MPI indices were calculated using the DEA software developed by Holger Scheel: EMS Version 1.3 (Scheel, 2000). C = Catching up effect; $F=$ Frontier shift effect; $M P I=$ Malmquist productivity index. 
In our analysis we also decided to explore the effect of scale economies on the sector. This was relevant for two main reasons. Firstly, the assumption of VRS was justified because the units vary considerably in size, and size seems to be an important factor in determining the cost structure of the units. A medium-large size unit may benefit from economies of scale regarding the installation and maintenance of the network. Furthermore, the analysis of the data showed that the operational costs are not proportional to the number of customers, suggesting the existence of variable returns to scale in this industry. Secondly, during the conduct of this research, the Portuguese electricity system has undergone a major transformation where the fourteen distribution areas were merged into six regional distribution centres. It was then considered important to determine the extent to which the results of the DEA would corroborate the views of the company that operating at a larger scale would be more productive.

In order to avoid lengthening the paper, we have chosen to focus our analysis on the results obtained for the most recent year of operation (2006). We have broken down the technical efficiency score into pure technical efficiency and scale efficiency. Table 3 shows these results.

TABle 3 - Efficiency Scores for Portuguese Electricity Distribution 2006

\begin{tabular}{ccccc}
\hline DMU & $\begin{array}{c}\text { Technical } \\
\text { Efficiency }\end{array}$ & $\begin{array}{c}\text { Pure } \\
\text { Technical } \\
\text { Efficiency }\end{array}$ & $\begin{array}{c}\text { Scale } \\
\text { Efficiency }\end{array}$ & $\begin{array}{c}\text { Returns } \\
\text { to Scale }\end{array}$ \\
\hline 1 & $77.12 \%$ & $78.65 \%$ & $98.05 \%$ & IRS \\
2 & $85.37 \%$ & $85.38 \%$ & $99.99 \%$ & IRS \\
3 & $76.30 \%$ & $82.09 \%$ & $92.95 \%$ & IRS \\
5 & $96.77 \%$ & $100.00 \%$ & $96.77 \%$ & IRS \\
6 & $100.00 \%$ & $100.00 \%$ & $100.00 \%$ & CRS \\
7 & $89.81 \%$ & $90.96 \%$ & $98.74 \%$ & DRS \\
8 & $93.45 \%$ & $100.00 \%$ & $93.45 \%$ & IRS \\
9 & $85.38 \%$ & $100.00 \%$ & $85.38 \%$ & IRS \\
10 & $82.27 \%$ & $94.15 \%$ & $87.38 \%$ & IRS \\
11 & $90.49 \%$ & $95.07 \%$ & $95.18 \%$ & IRS \\
12 & $86.00 \%$ & $100.00 \%$ & $100.00 \%$ & CRS \\
13 & $100.00 \%$ & $100.00 \%$ & $86.45 \%$ & IRS \\
14 & $67.74 \%$ & $82.52 \%$ & $82.09 \%$ & CRS \\
IRS \\
\hline Average & $87.94 \%$ & $93.49 \%$ & $94.03 \%$ & \\
Min & $67.74 \%$ & $78.65 \%$ & $82.09 \%$ & \\
Max & $100.00 \%$ & $100.00 \%$ & $100.00 \%$ & \\
St Dev & $9.9 \%$ & $8.1 \%$ & $6.3 \%$ & \\
\hline Note: IRS $=$ inceasing returns to scale; CRS $=$ constant returns to scale; DRS = decreasing returns to scale.
\end{tabular}

In 2006, the average total efficiency score of the 14 distribution units was around $88 \%$, with a standard deviation of approximately $10 \%$, which suggests that there may be some potential for improvement in some of the units.

In our study, in 2006, only 3 units are classified as CRS efficient. When we allow VRS, the number of efficient units increases to 7 . This means that we have 4 units (DMUs 4, 7, 8 and 12) that are technically efficient whilst operating under sub optimal scale sizes. All these units operate under increasing returns to scale (IRS), which suggests that a greater scale of operation would lead to a greater ratio of outputs over inputs.

With regards to the units that are technically inefficient, we can verify that distribution units 14 and 9 are the units that could benefit most from increasing their size of operation. Part of their 
inefficiency is due to their scale of operation. On the contrary, distribution unit 1 shows the lowest score in terms of technical efficiency. This unit could benefit mostly from a better use of its inputs, basically maintaining its size of operation. Distribution unit 13 is the most relevant peer for distribution unit 1.

Distribution unit 6 is the only one that operates under decreasing returns to scale (DRS) suggesting that a smaller scale of operation would lead to a greater ratio of outputs over inputs. One can note that distribution unit 6 presents the maximum network length.

The fact that most DMUs were classified by DEA as operating under IRS was regarded as highly relevant as it largely corroborated the decision made by the company of merging the previous distribution areas into larger distribution centres. This fact was also important to legitimise the results obtained and improve the face validity of the models adopted. Further research will explore the extent to which merging affected the efficiency of the distribution areas.

Three of the 'new' distribution centres resulted exclusively from the merging of DMUs operating under IRS. It is, therefore, expected that they will achieve gains in efficiency by operating at a larger size. Another of the 'new' distribution centres resulted from the merging of two of the technically efficient distribution areas. Considering that these areas were already efficient in the conversion of their resources into results, it is anticipated that they will continue to show evidence of good performance. The remaining two 'new' centres resulted from the merging of DMUs operating at different scale sizes, and therefore, it will be valuable to explore how the performance of the 'new' centres will be affected by merging. Whilst it will be difficult to assess the efficiency of these 'new' centres by means of the DEA, as we have only six DMUs, we intend to carry out some in-depth case study analysis to do so.

\subsection{Using slacks based efficiency measurement to estimate the implicit production trade-offs} between the variables

To conclude our analysis and given the interest in exploring the production trade-offs between some of the inputs and outputs in the EDP production process, we have decided to also undertake a Slack Based Measurement (SBM) of efficiency, as proposed by Tone (2001), with the variables used in the model discussed earlier. The efficiency score in the SBM can be interpreted as the average feasible rate of reduction in inputs relative to the average feasible rate of expansion in outputs. When compared with the Charnes, Cooper and Rhodes (CCR) model, the SBM model adjusts the efficiency scores downwards to account for the slacks. As demonstrated by Tone (2001), a DMU classified as efficient by the SBM model will also be classified as efficient by the CCR model, but the reverse is not true. Our interest in applying the SBM model to the EDP context lies in the useful profit interpretation of its dual programme. Whilst the dual of the CCR model aims to maximise the virtual ratio of outputs over inputs, the dual of the SBM model aims to maximise the virtual profit (with a maximum virtual profit of zero). In this respect, the weights obtained from the SBM can be interpreted as virtual costs of inputs and virtual prices of outputs. The results from the SBM model, with the two weight restrictions discussed earlier, are presented in Table 4. 
TABLE 4 - RESULtS FROM THE SBM MOdEL AFTER INTRODUCING WEIGHT RESTRICTIONS IN 2006

\begin{tabular}{ccccccccccc}
\hline & & & \multicolumn{4}{c}{ Weighted data } & \multicolumn{4}{c}{ Trade-offs } \\
DMU & Efficiency & Virtual Profit & $\mathrm{X}_{1}$ & $\mathrm{X}_{2}$ & $\mathrm{X}_{3}$ & $\mathrm{Y}_{1}$ & $\mathrm{Y}_{2}$ & $\eta_{1} / \xi_{1}$ & $\xi_{1} / \eta_{2}$ \\
\hline & & & & & & & & & \\
\hline 1 & $63.61 \%$ & -0.3639 & 0.3333 & 0.3333 & 0.3333 & 0.3181 & 0.3181 & 61.83 & 73730 \\
2 & $61.91 \%$ & -0.3809 & 0.3333 & 0.3333 & 0.3333 & 0.3095 & 0.3095 & 78.57 & 83420 \\
3 & $59.46 \%$ & -0.4054 & 0.3333 & 0.3333 & 0.3333 & 0.2973 & 0.2973 & 55.85 & 58304 \\
4 & $75.07 \%$ & -0.2493 & 2.4085 & 0.3333 & 1.7943 & 0.3754 & 3.9115 & 169.05 & 84000 \\
5 & $100.00 \%$ & 0.0000 & 2.1758 & 0.3333 & 1.8370 & 0.5000 & 3.8461 & 168.64 & 84000 \\
6 & $51.86 \%$ & -0.4814 & 0.3607 & 0.3333 & 0.7236 & 0.6770 & 0.2593 & 40.00 & 84000 \\
7 & $74.42 \%$ & -0.2558 & 0.3063 & 0.3333 & 0.4385 & 0.4502 & 0.3721 & 40.00 & 84000 \\
8 & $71.79 \%$ & -0.2821 & 0.2758 & 0.3333 & 0.3333 & 0.3014 & 0.3589 & 58.63 & 84000 \\
9 & $61.80 \%$ & -0.3820 & 0.3333 & 0.3333 & 0.3333 & 0.2094 & 0.4086 & 56.11 & 84000 \\
10 & $74.50 \%$ & -0.2550 & 0.6734 & 0.3333 & 0.3333 & 0.0000 & 1.0850 & large & 84000 \\
11 & $100.00 \%$ & 0.0000 & 40.1625 & 53.9850 & 0.3333 & 93.9808 & 0.5000 & 40.00 & 971 \\
12 & $83.25 \%$ & -0.1675 & 0.3333 & 0.3333 & 0.3333 & 0.3446 & 0.4879 & 69.20 & 84000 \\
13 & $100.00 \%$ & 0.0000 & 0.3333 & 0.3333 & 0.3333 & 0.5000 & 0.5000 & 63.81 & 70765 \\
14 & $53.74 \%$ & -0.4626 & 0.3333 & 0.3333 & 0.3333 & 0.2687 & 0.2687 & 54.78 & 63668 \\
\hline Note: $\eta_{i}$ is the weight associated with output $i$ and $\xi_{j}$ is the weight associated with input $j$ in the slack based model.
\end{tabular}

In our example, all the units classified as efficient by the CCR model maintain their efficient status with the SBM model. DMUs 5, 11 and 13 are classified as efficient, presenting the maximum virtual profit of zero. Nevertheless, the contribution of the various inputs and outputs to the virtual profit is not similar across these three DMUs. Whilst DMU 13 arrives at an optimal virtual profit using a balanced distribution across the inputs and a balanced distribution across the outputs, DMU 5 and DMU 11 value very differently each of the variables included in the model. If we focus on the output side, for example, we conclude that, the electricity distributed is the output that most contributes to the virtual profit of DMU 11 and the quality of the service delivered is the output that most contributes to the virtual profit of DMU 5. In that respect, whilst DMU 11 values one minute of interruption time in 971 euros, DMU 5 values it in 84000 euros (which is the maximum allowed by the second restriction imposed). In contrast, with an extra euro spent on operational costs, DMU 5 is able to distribute 169 units of electricity and DMU 11 is only able to distribute 40 units of electricity (which is the minimum required by the first restriction imposed). If we focus on the input side, in order to be classified as efficient, DMU 5 places the highest valuation in the operational costs and the lowest valuation in the length of network, whilst DMU 11 places the highest internal valuation in the length of network and the lowest valuation in the transformers' capacity.

With regard to the inefficient networks, the application of the SBM model implied a decrease in their efficiency scores due to the existence of input and output slacks. When we analyse the contribution of the two outputs to the virtual profit of these networks, it is possible to identify three distinct groups. The first group is constituted by those networks that value evenly the two outputs (DMUs 1, 2, 3 and 14). The second group is formed by those networks that place a relatively higher valuation in the quality of service (DMUs $4,8,9,10$ and 12). The third group is formed by the networks that place a relatively higher valuation in the quantity of energy delivered (DMUs 6 and 7 ). 
Analyses of the implicit trade-offs for each of the inefficient networks can also offer interesting insights. Network 6, for example, presents the lowest score in terms of SBM (around 52\%), having decreased from around $90 \%$ in the radial model. This network places a higher valuation in the energy delivered because it presents the poorest quality of service from the set. In the radial model, it was the only network which presented a slack in the output capturing the quality of service. The low standard of service quality, together with the fact that Network 6 was forced to accept the minimum production trade-offs imposed by the two weight restrictions, led to a very low score.

\section{Discussion and Conclusion}

Data envelopment analysis is probably one of the most widespread OR/MS techniques to compare the performance of organisational units and its use in the electricity sector has been prolific. A review of the literature shows around 33 publications in refereed journals just in the last decade, with 6 of these being published in the last year. However, while numerous studies have been documented, they have been predominantly descriptive and classificatory. It is not always clear from the literature what the involvement of the stakeholders in the process was, and what the major stakeholders learnt from it.

This research had a two-goal purpose. The first goal was aimed at analysing the efficiency of the Portuguese electricity distribution units for the period 2002-2006, as well as assessing productivity changes over this period. This was an important outcome as the number of published studies is very limited and no published studies are available on productivity changes of the Portuguese electricity sector over time. Furthermore, in the last 3 years, the group responsible for electricity distribution in Portugal has applied a severe cost cutting exercise and implemented an efficiency improvement programme in order to become the most efficient energy provider in Iberia. There was, therefore, a great interest in assessing the extent to which these efforts would be reflected in the results of our analysis and also to identify and study the distribution areas that best succeeded in implementing this programme.

From our cross-section analysis we concluded that whilst there are some efficient units in the sector, there are some regions that could benefit from a benchmarking exercise in order to improve their efficiency. In some regions this problem was mainly a technical efficiency problem, suggesting that all inputs could be reduced maintaining the current level of service provision. In other regions there was evidence of scale inefficiencies, suggesting that the units could benefit from altering their scale of operation. In addition, the Malmquist Indices calculated showed an $11 \%$ productivity improvement from 2002 to 2006 . This improvement was due to a frontier shift, providing evidence of innovation in this industry. Nevertheless, on average, the distance of the individual units to the frontier increased over time, showing some decay in the average level of the utilities' efficiency. This suggests that some of the regions found it difficult to keep up with the improvements in technology.

Although the structure in which the electricity distribution sector in Portugal is organised has changed during this research, we believe that these results may provide useful information for 
policy making, contributing to the development of programmes aimed at improving the efficiency of the distribution utilities across the country and improving productivity in this sector. Furthermore, the inclusion of information regarding the quality of the service delivered in the performance assessment models, as considered in the current study, is of paramount importance to ensure that the productivity gains found in the sector can also be beneficial to the customers.

The second goal of this research was aimed at exploring the use of DEA in a formative rather than summative way. In particular, and considering that one of the authors is a member of the organisation assessed, we aimed at involving some influential decision makers at key stages of the process, and discussing with them not only the models but also the results produced.

The case study intervention, however, met several difficulties. In particular, it showed that whilst the modelling of productivity/efficiency scores using DEA is relatively straightforward, it is comparatively more difficult to develop models that are economically valid and that produce results with face validity. In what follows we discuss some of the major issues raised during this research in terms of the use of DEA with formative purposes.

The correct specification of the DEA models is an issue which several authors have addressed and pointed out as a requirement to obtain meaningful results. This issue is particularly relevant whenever there is no consensus regarding the appropriate set of inputs and outputs to use. In that respect, the involvement of the decision makers throughout the process is essential to develop models with face validity. In the analysis of efficiency in the electricity distribution industry, for example, the literature shows that some authors have included the variable 'service area' as an output in their models, whilst others have not considered it. When faced with the choice between the two options, and considering the difficulty in establishing meaningful production trade-offs involving this variable, the decision makers taking part in our study, chose to exclude it. However, the results we have obtained show that the decision to include or exclude the variable 'service area' is important because it has an impact on the results. Considering the difficulty in establishing meaningful production trade-offs between discretionary and non discretionary variables in this context, whenever the latter variables are considered important for the efficiency analysis, the best protocol might be to undertake separate analysis between units located in urban and rural areas (the number of DMUs permitting), rather than excluding the variables.

The correct specification of the models is also fundamental when the analyst, or the facilitator developing the DEA models, has to address some of the DEA 'pitfalls'. While alternative protocols have been suggested to address these pitfalls (e.g. Dyson et al, 2001), our analysis has shown that some might not be acceptable to the decision makers. Considering that the acceptability of the results is an important step to implementation, whenever no universal protocol exists, it is fundamental for the analyst to discuss these protocols with the decision makers. Furthermore, while different protocols might be adopted, it is important to bear in mind that they can lead to different outcomes not only in terms of the DMUs identified as efficient but also in terms of the targets set for inefficient units. A thorough analysis of the sensibility of the results to different protocols is recommended.

The issue of the targets set by the DEA analysis also deserves some consideration here. It is 
reasonable to assume that in carrying out efficiency studies there will be some variables over which the DMUs exercise some degree of control. These will be considered discretionary variables. However, whilst this control exists, it might be limited. This fact imposes some restrictions regarding the implementation of some of the targets suggested by the DEA analysis as these targets might not be realistically achievable. Whilst there are procedures in the DEA literature to address this issue (e.g. Golany and Roll, 1993), the implementation of these procedures in practice is not a straightforward task as the decision makers show some reluctance in being explicit about the degree of control they have over a variable. Further research dealing with procedures to elicit this type of information from the decision makers would be valuable.

Another issue where elicitation procedures would be welcome is related to the weight restrictions. Our study corroborates some evidence that giving total flexibility to the DMUs in the choice of weights might produce results without face validity. As has been widely suggested, this issue can be addressed by the use of weight restrictions. The definition of weight restrictions, in particular if they involve the specification of production trade-offs might, however, prove a difficult task. Whilst several approaches to define weight restrictions exist, the use of production trade-offs is the only one that allows the efficiency scores to maintain their radial interpretation. However, the specification of production trade-offs can be a very challenging task. Decision makers show considerable resistance in expressing production trade-offs between variables. The Multicriteria Decision Analysis literature is very rich regarding procedures to elicit the preferences of the decision makers. Further research can explore the extent to which some of these procedures can be used in the DEA context to express weight restrictions that are economically valid and that derive from the preferences of the decision makers.

Finally, at several stages of the process it became apparent that the decision makers implicitly use global rather than local scales to compare the distribution areas, and that they would consider it important to establish fixed weights to compare all the DMUs. Future research on these issues would be also valuable.

Overall, despite the challenges in the development of the models, the participants recognised that the final DEA model proposed represents a more comprehensive system to monitor the performance of the different electricity distribution units than the one in use at the company and that it offered a valuable learning exercise. As a result of this learning, the company is currently implementing a DEA analysis for the formative evaluation of its 25 operational areas and to compare the efficiency of 79 distribution lines.

It is important to emphasise that despite the fact that the successful application of DEA in practice can be a challenge, DEA has a strong potential to contribute for performance improvement. In particular, DEA is well suited to substitute or complement efficiency analyses undertaken by means of other benchmarking methodologies as, for example, regression methods (see, for example, Pollitt, 2005). The main relative advantage of DEA, when compared with regression based methods, is the fact that it does not rely on averaging methods; instead it identifies a best practice frontier based on actual observations, with only a minimum set of assumptions. Furthermore, the DEA technique allows the analyst to distinguish between various 
sources of inefficiency: pure technical, allocative and scale. When panel data is available, the Malmquist index also allows the decomposition of productivity growth into frontier technical change and firm efficiency catch-up. These advantages of DEA as a benchmarking technique may explain the fact that this is the technique most often used by European, Australasian and Latin American regulators for efficiency analysis of electricity distribution utilities (Haney and Pollitt, 2009).

In conclusion, we believe that DEA is a strong analytical technique upon which to build. However, one of the premises of this paper is that DEA has to be broadened in order to contribute to performance improvement in practice. One of the main aspects of this broadening relates to the need to move away from the 'black box' type of evaluation, by incorporating the DEA exercise into case studies and context-driven research projects in order to facilitate the development of appropriate models and the implementation of the results in practice. 


\section{APPENDIX}

TABLE A

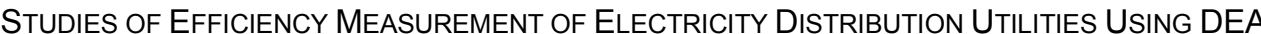

\begin{tabular}{|c|c|c|c|c|}
\hline Study & DMUs & Inputs & Outputs & Environmental Variables \\
\hline Charnes et al (1989) & $\begin{array}{l}\text { Regulated electricity cooperatives in } \\
\text { Texas. }\end{array}$ & $\begin{array}{l}\text { (1) Operations expense; (2) Maintenance expense; } \\
\text { (3) Consumer accounts expense; (4) Administrative and } \\
\text { general expense; (5) Miles per consumer; (6) Line losses; } \\
\text { (7) Average hours outage per consumer; (8) Percent system } \\
\text { unload; (9) Total plant; (10) Salaries; (11) Inventory. }\end{array}$ & $\begin{array}{l}\text { (1) Net margin; (2) Total Kwh sales; (3) Total } \\
\text { revenue from sales of electricity. }\end{array}$ & \\
\hline Weyman-Jones (1991) & $\begin{array}{l}12 \text { public energy distribution companies in } \\
\text { England and Wales. }\end{array}$ & $\begin{array}{l}\text { Model } 1 \\
\text { (1) Total value of company area assets; (2) Man-hours. } \\
\text { Model } 2 \\
\text { (1) Amount of main distributions in service (circuit-km); } \\
\text { (2) Man-hours. }\end{array}$ & $\begin{array}{l}\text { Model } 1 \text { and 2: } \\
\text { (1) Retail sales to domestic consumers (KWh); } \\
\text { (2) Retail sales to commercial consumers }(\mathrm{KWh}) \text {; } \\
\text { (3) Retail sales to industrial consumers (KWh). }\end{array}$ & \\
\hline $\begin{array}{l}\text { Hjalmarsson and } \\
\text { Veiderpass (1992) }\end{array}$ & $\begin{array}{l}\text { Between } 73 \text { and } 162 \text { retail electricity } \\
\text { distributors in Sweden, depending on the } \\
\text { year of analysis. }\end{array}$ & $\begin{array}{l}\text { (1) Hours worked (h) by all employees; (2) Low voltage } \\
\text { power lines (km); (3) High voltage power lines }(\mathrm{km}) \text {; } \\
\text { (4) Total transformer capacity (kVA). }\end{array}$ & $\begin{array}{l}\text { (1) Low voltage electricity (MWh) received by } \\
\text { customers; ( } 2 \text { ) High voltage electricity (MWh) } \\
\text { received by customers; (3) Number of low voltage } \\
\text { electricity customers; (4) Number of high voltage } \\
\text { electricity customers. }\end{array}$ & \\
\hline Miliotis (1992) & $\begin{array}{l}45 \text { electricity distribution districts of Greek } \\
\text { Public Power Corporation. *The inputs } \\
\text { and outputs were combined in four } \\
\text { different models. }\end{array}$ & $\begin{array}{l}\text { (1) Network length }(\mathrm{km}) ; \quad(2) \text { Capacity of installed } \\
\text { transformation points (kva); (3) General expenses (dollars); } \\
\text { (4) Administrative labour (hours); (5) Technical labour } \\
\text { (hours). }\end{array}$ & $\begin{array}{l}\text { (1) Number of customers served; (2) Energy } \\
\text { supplied (KWh); (3) Served area }\left(\mathrm{km}^{2}\right) \text {. }\end{array}$ & \\
\hline Pollitt (1995) & $\begin{array}{l}\text { Australia, Canada, Denmark, Germany, } \\
\text { Greece, Hong Kong, Ireland, Japan, New } \\
\text { Zealand, South Africa, Thailand, Taiwan, } \\
\text { United Kingdom, USA. }\end{array}$ & $\begin{array}{l}\text { (1) Number of employees; (2) Network extension (km); } \\
\text { (3) Transformers' capacity (MVA). }\end{array}$ & $\begin{array}{l}\text { (1) Number of clients; (2) Residential sales (MWh); } \\
(3) \text { Non-residential sales (MWh); (4) Service area } \\
\left(\mathrm{km}^{2}\right) \text {; (5) Maximum demand (MW). }\end{array}$ & \\
\hline \multirow[t]{2}{*}{ Weyman-Jones (1995) } & \multirow[t]{2}{*}{ United Kingdom. } & $\begin{array}{l}\text { Model } 1 \\
\text { (1) Number of employees; (2) Network extension (km); } \\
\text { (3) Transformers' capacity (MVA). }\end{array}$ & $\begin{array}{l}\text { Model } 1 \\
\text { (1) Residential sales (kWh); (2) Commercial sales } \\
(\mathrm{kWh}) \text {; (3) Industrial sales (kWh); (4) Maximum } \\
\text { demand (kW). }\end{array}$ & \multirow{2}{*}{$\begin{array}{l}\text { (1) Network extension (km); } \\
\text { (2) Transformer's capacity } \\
\text { (MVA); (3) Total sales (kWh); } \\
\text { (4) Maximum demand (kW); } \\
\text { (5) Population density; (6) } \\
\text { Industrial sales as proportion } \\
\text { to total sales. }\end{array}$} \\
\hline & & (1) Number of employees. & $\begin{array}{l}\text { Model } 2 \\
\text { (1) Number of clients. }\end{array}$ & \\
\hline $\begin{array}{l}\text { Bagdadioglu, Price and } \\
\text { Weyman-Jones (1996) }\end{array}$ & $\begin{array}{l}70 \text { organisations in the Turkish electricity } \\
\text { distribution sector. }\end{array}$ & $\begin{array}{l}\text { (1) Manpower; (2) Transformer capacity; (3) Network size; } \\
\text { (4) General expenses; (5) Network losses. }\end{array}$ & $\begin{array}{l}\text { (1) Number of customers; (2) Electricity supplied; } \\
\text { (3) Maximum demand; (4) Service area. }\end{array}$ & \\
\hline $\begin{array}{l}\text { Førsund and Kittelsen } \\
\text { (1998) }\end{array}$ & $\begin{array}{l}157 \text { electricity utilities engaged in local } \\
\text { retail distribution in Norway in } 1983 \text { and } \\
170 \text { in } 1989 .\end{array}$ & $\begin{array}{l}\text { (1) Labour (h); (2) Energy loss (MWh); (3) Capital (1000 } \\
\text { NoK); (4) Materials (1000 NoK). }\end{array}$ & $\begin{array}{l}\text { (1) Distance index expressing density of } \\
\text { customers; (2) Number of customers; (3) Total } \\
\text { energy delivered (MWh). }\end{array}$ & \\
\hline
\end{tabular}




\begin{tabular}{|c|c|c|c|c|}
\hline Study & DMUs & Inputs & Outputs & Environmental Variables \\
\hline \multirow[t]{2}{*}{$\begin{array}{l}\text { Kumbhahar and } \\
\text { Hjalmarsson (1998) }\end{array}$} & $\begin{array}{l}\text { Swedish electricity retail distributors in } \\
\text { Sweeden. }\end{array}$ & $\begin{array}{l}\text { Model } 1 \\
\text { (1) Full time equivalent employees; (2) Total transformers' } \\
\text { capacity (KVA); (3) Kilometres of high voltage lines; } \\
\text { (4) Kilometres of low voltage lines. }\end{array}$ & $\begin{array}{l}\text { Model } 1 \\
\text { (1) Low voltage electricity in MWhs received by the } \\
\text { customers; (2) High voltage electricity in MWhs } \\
\text { received by the customers. }\end{array}$ & \\
\hline & & $\begin{array}{l}\text { Model } 2 \\
\text { (1) Full time equivalent employees; (2) Total transformer } \\
\text { capacity (KVA). }\end{array}$ & $\begin{array}{l}\text { Model } 2 \\
\text { (1) Low voltage electricity in MWhs received by the } \\
\text { customers; (2) High voltage electricity in MWhs } \\
\text { received by the customers; (3) Kilometres of high } \\
\text { voltage lines; (4) Kilometres of low voltage lines; } \\
\text { (5) Transformers' capacity (kVA). }\end{array}$ & \\
\hline Zhang and Bartels (1998) & $\begin{array}{l}32 \text { Electricity Supply Authorities in } \\
\text { Australia, } 51 \text { Electricity Power Boards in } \\
\text { New Zealand, and } 173 \text { Swedish Retail } \\
\text { Electricity Distributors (considered } \\
\text { separately). }\end{array}$ & $\begin{array}{l}\text { (1) Number of employees; (2) Total kilometres of distribution } \\
\text { lines; (3) Total transformers' capacity (MVA). }\end{array}$ & (1) Total number of customers served. & \\
\hline Lo, Chien and Lin (2001) & $\begin{array}{l}22 \text { electricity distribution districts in } \\
\text { Taiwan Power Company. }\end{array}$ & $\begin{array}{l}\text { (1) Employment expenditure; (2) General expenditure; } \\
\text { (3) Total assets; (4) Distribution network; (5) Transformer } \\
\text { capacity. }\end{array}$ & (1) Number of customers; (2) Energy supplied. & \\
\hline Chen (2002) & $\begin{array}{l}22 \text { distribution districts in Taiwan. } \\
{ }^{*} \text { The input and output variables are } \\
\text { combined in } 8 \text { different models. }\end{array}$ & $\begin{array}{l}\text { (1) Manpower of the electricity distribution district; (2) Total } \\
\text { transformer capacity (MVA); (3) System network size, total } \\
\text { power lines (km); (4) General expenses. }\end{array}$ & $\begin{array}{l}\text { (1) Number of low voltage electricity customers; } \\
\text { (2) Number of high voltage electricity customers; } \\
\text { (3) Low voltage electricity supply (MWh); (4) High } \\
\text { voltage electricity supply (MWh); (5) Maximum } \\
\text { demand (MW); (6) Total revenue by electricity } \\
\text { supplied. }\end{array}$ & \\
\hline $\begin{array}{l}\text { Pacudan and de Guzman } \\
\text { (2002) }\end{array}$ & $\begin{array}{l}15 \text { electricity distribution utilities in } \\
\text { Philippines. }\end{array}$ & $\begin{array}{l}\text { (1) Number of employees; (2) Network losses; (3) Length of } \\
\text { network line. }\end{array}$ & $\begin{array}{l}\text { (1) Number of customers; (2) Service area; } \\
\text { (3) Electricity sales. }\end{array}$ & \\
\hline $\begin{array}{l}\text { Pahwa, Feng and } \\
\text { Lubkerman (2002) }\end{array}$ & $\begin{array}{l}\text { The } 50 \text { largest electricity distributions } \\
\text { utilities in the USA. }\end{array}$ & $\begin{array}{l}\text { (1) Distribution systems losses; (2) Distribution operation } \\
\text { and maintenance expenses; (3) Distribution capital addition } \\
\text { expenses; (4) Distribution line transformers; (5) Distribution } \\
\text { lines. }\end{array}$ & $\begin{array}{l}\text { (1) Distribution system peak load; (2) Retail sales; } \\
\text { (3) Retail customers. }\end{array}$ & \\
\hline \multirow[t]{2}{*}{ Resende (2002) } & 24 electricity distribution firms in Brazil. & $\begin{array}{l}\text { Model } 1 \text { and 2: } \\
\text { (1) Number of employees; (2) Tranformers' capacity (MVA); } \\
\text { (3) Network extension }(\mathrm{km}) \text {. }\end{array}$ & $\begin{array}{l}\text { Model 1: } \\
\text { (1) Concession area (in } \mathrm{km}^{2} \text { ); (2) Number of } \\
\text { consumers; (3) Industrial sales of electric energy } \\
\text { (MWh); (4) Non-industrial sales of electric energy } \\
\text { (MWh). }\end{array}$ & \\
\hline & & & $\begin{array}{l}\text { Model 2: } \\
\left.\text { (1) Concession area (in } \mathrm{km}^{2}\right) ;(2) \text { Industrial sales of } \\
\text { electric energy ( } \mathrm{MWh}) ;(3) \text { Non-industrial sales of } \\
\text { electric energy }(\mathrm{MWh}) \text {. }\end{array}$ & \\
\hline Chien, Lo and Lin (2003) & $\begin{array}{l}17 \text { service centres of the NAN-TOU } \\
\text { electricity distribution district of the } \\
\text { Taiwan Power Company. }\end{array}$ & $\begin{array}{l}\text { (1) Number of staff (person); (2) Value of general equipment } \\
\text { (NT\$ } 10,000) \text {. }\end{array}$ & $\begin{array}{l}\text { (1) Number of customers; (2) Distribution network } \\
\text { (km); (3) Transformer capacity (KVA). }\end{array}$ & \\
\hline
\end{tabular}




\begin{tabular}{|c|c|c|c|c|}
\hline Study & DMUs & Inputs & Outputs & Environmental Variables \\
\hline $\begin{array}{l}\text { Edvardsen and Førsund } \\
\text { (2003) }\end{array}$ & $\begin{array}{l}122 \text { distribution utilities from Denmark, } \\
\text { Finland, Norway, Sweden and } \\
\text { Netherlands. }\end{array}$ & $\begin{array}{l}\text { (1) Total operating and maintenance costs; (2) Energy lost } \\
\text { due to interruptions; (3) Power lines network (km); } \\
\text { (4) replacement value. }\end{array}$ & (1) Number of customers; (2) Energy delivered. & \\
\hline \multirow[t]{2}{*}{ Jamasb and Pollitt (2003) } & $\begin{array}{l}63 \text { electricity distribution and regional } \\
\text { transmission utilities in Italy, Norway, UK, } \\
\text { Portugal, Spain and The Netherlands. }\end{array}$ & $\begin{array}{l}\text { Model 1: } \\
\text { (1) Total costs. }\end{array}$ & $\begin{array}{l}\text { Model 1: } \\
\text { (1) Units of electricity delivered; (2) Number of } \\
\text { customers; (3) Network length. }\end{array}$ & \\
\hline & & $\begin{array}{l}\text { Model 2: } \\
\text { (1) Operating costs; (2) Network length; (3) Energy lost in } \\
\text { transmission. }\end{array}$ & $\begin{array}{l}\text { Model 2: } \\
\text { (1) Units of electricity delivered; (2) Number of } \\
\text { customers. }\end{array}$ & \\
\hline $\begin{array}{l}\text { Korhonen and Syrjänen } \\
(2003)\end{array}$ & $\begin{array}{l}102 \text { electricity distribution companies in } \\
\text { Finland. }\end{array}$ & (1) Operating costs. & $\begin{array}{l}\text { (1) Units of electricity distributed; (2) 3-year } \\
\text { average of total interruption time. }\end{array}$ & $\begin{array}{l}\text { (1) Total network length; (2) } \\
\text { Number of customers; (3) } \\
\text { Average snow depth in winter } \\
\text { and } \mathrm{km}^{2} \text { of forest cover. }\end{array}$ \\
\hline $\begin{array}{l}\text { Estache, Rossi and Ruzzier } \\
(2004)\end{array}$ & $\begin{array}{l}84 \text { electricity distribution firms in South } \\
\text { America. }\end{array}$ & $\begin{array}{l}\text { (1) Number of employees; (2) Transfer capacity; (3) Network } \\
\text { length (km). }\end{array}$ & $\begin{array}{l}\text { (1) Number of final customers; (2) Total energy } \\
\text { supplied to final customers; (3) Service area. }\end{array}$ & $\begin{array}{l}\text { (1) Residential sales share; } \\
\text { (2) GNP per capita. }\end{array}$ \\
\hline $\begin{array}{l}\text { Sanhueza, Rudnick, and } \\
\text { Lagunas (2004) }\end{array}$ & $\begin{array}{l}35 \text { electricity distribution companies in } \\
\text { Chile. }\end{array}$ & $\begin{array}{l}\text { (1) Real distribution added value }(\$ / \mathrm{kW} / \mathrm{year}) \text { Total } \\
\text { kilometres of distribution lines; Energy that has not been } \\
\text { billed; (4) Number of workers; (5) Salaries. }\end{array}$ & $\begin{array}{l}\text { (1) Total energy sold; (2) Coincident power during } \\
\text { peak hours; (3) Number of customers. }\end{array}$ & \\
\hline \multirow[t]{2}{*}{$\begin{array}{l}\text { Agrell, Bogetoft and Tind } \\
\text { (2005) }\end{array}$} & $\begin{array}{l}238 \text { electricity distribution concessions in } \\
\text { Sweden. }\end{array}$ & $\begin{array}{l}\text { Long Term Model: } \\
\begin{array}{ll}\text { (1) Operating expenditures; } & \text { (2) Capital expenditures; } \\
\text { (3) Net losses (MWh). }\end{array}\end{array}$ & $\begin{array}{l}\text { Long Term Model: } \\
\text { (1) Coincidental peak load (MW); (2) Number of } \\
\text { high-voltage connections; ( } 3 \text { ) Number of low- } \\
\text { voltage connections; (4) Net delivered high-voltage } \\
\text { energy; (5) Net delivered low-voltage energy. }\end{array}$ & $\begin{array}{l}\text { (1) Climate zone (categorical, } \\
\text { z); (2) Normalized net length } \\
(\mathrm{km}) \text {. }\end{array}$ \\
\hline & & $\begin{array}{l}\text { Short Term Model: } \\
\text { (1) Operating expenditures + the supplementary cost above } \\
\text { market price for electricity. }\end{array}$ & $\begin{array}{l}\text { Short Term Model: } \\
\text { (1) Coincidental peak load (MW); ( } 2 \text { ) Number of } \\
\text { high-voltage connections; ( } 3 \text { ) Number of low- } \\
\text { voltage connections; (4) Net delivered high-voltage } \\
\text { energy; (5) Net delivered low-voltage energy. }\end{array}$ & $\begin{array}{l}\text { (1) Network length (km); } \\
\text { (2) Total energy net losses (in } \\
\text { MWh). }\end{array}$ \\
\hline \multirow[t]{2}{*}{ Berg, Lin and Tsaplin (2005) } & $\begin{array}{l}24 \text { electricity distribution companies in } \\
\text { Ukraine }\end{array}$ & $\begin{array}{l}\text { Model 1: } \\
\text { (1) Operational costs; (2) Network length. }\end{array}$ & $\begin{array}{l}\text { Model } 1 \text { and 2: } \\
\text { (1) Number of customers; (2) Electricity delivered. }\end{array}$ & \\
\hline & & $\begin{array}{l}\text { Model 2: } \\
\text { (1) Electricity purchased; (2) Operational costs; (3) Network } \\
\text { length. }\end{array}$ & & \\
\hline \multirow[t]{4}{*}{$\begin{array}{l}\text { Giannakis, Jamasb and } \\
\text { Pollitt (2005) }\end{array}$} & $\begin{array}{l}\text { The } 14 \text { distribution network operators in } \\
\text { the United Kingdom. }\end{array}$ & $\begin{array}{l}\text { Model 1: } \\
\text { (1) Operating expenditures. }\end{array}$ & \multirow{4}{*}{$\begin{array}{l}\text { Model 1, 2, } 3 \text { and 4: } \\
\text { (1) Total number of customers; (2) Units of energy } \\
\text { delivered; (3) Total network length. }\end{array}$} & \\
\hline & & $\begin{array}{l}\text { Model 2: } \\
\text { (1) Total expenditures. }\end{array}$ & & \\
\hline & & $\begin{array}{l}\text { Model 3: } \\
\text { (1) Number of interruptions; (2) Customer time lost due to } \\
\text { interruptions. }\end{array}$ & & \\
\hline & & $\begin{array}{l}\text { Model 4: } \\
\text { (1) Total expenditures; (2) Number of interruptions; } \\
\text { (3) Customer time lost due to interruptions. }\end{array}$ & & \\
\hline
\end{tabular}




\begin{tabular}{|c|c|c|c|c|}
\hline Study & DMUs & Inputs & Outputs & Environmental Variables \\
\hline $\begin{array}{l}\text { Hattori, Jamasb and Pollitt } \\
\text { (2005) }\end{array}$ & $\begin{array}{l}21 \text { utilities (12 UK regional electricity } \\
\text { distribution companies and } 9 \text { Japanese } \\
\text { electricity utilities). }\end{array}$ & (1) Total expenditures. & $\begin{array}{l}\text { (1) Number of customers; (2) Electricity units } \\
\text { delivered in megawatt-hours (MWh). }\end{array}$ & $\begin{array}{l}\text { (1) Customer density and load } \\
\text { factor. }\end{array}$ \\
\hline Yang and Lu (2006) & $\begin{array}{l}24 \text { electricity distribution districts of } \\
\text { Taiwan Power Company. }\end{array}$ & $\begin{array}{l}\text { (1) Employment expenditures; (2) Operating expenditures; } \\
\text { (3) Total assets; (4) Length of distribution network; } \\
\text { (5) Transformer capacity. }\end{array}$ & $\begin{array}{l}\text { (1) Number of customers; (2) Quantity of energy } \\
\text { sold; (3) Energy loss rate. }\end{array}$ & \\
\hline Pombo and Taborda (2006) & $\begin{array}{l}12 \text { large electricity distribution companies } \\
\text { in Colombia. }\end{array}$ & $\begin{array}{l}\text { (1) Employees in power distribution + commercialisation; } \\
\text { (2) Number of transformers + substations; (3) Power lines } \\
\text { network }(\mathrm{km}) \text {. }\end{array}$ & (1) Total sales (GWh); (2) Total customers. & $\begin{array}{l}\text { (1) Regional GDP per capita; } \\
\text { (2) National installed capacity } \\
\text { in electricity generation; } \\
\text { (3) Urban area served. }\end{array}$ \\
\hline $\begin{array}{l}\text { Tanur, Tahan and Lima } \\
\text { (2006) }\end{array}$ & 7 main distributing companies in Brazil. & $\begin{array}{l}\text { (1) Length of line }(\mathrm{km}) ;(2) \text { Installed transformers capacity } \\
\text { (MVA); (3) Operating and maintenance costs. }\end{array}$ & $\begin{array}{l}\text { (1) Customer average interruption duration index; } \\
\text { (2) Customer average interruption frequency. }\end{array}$ & \\
\hline \multirow[t]{2}{*}{$\begin{array}{l}\text { Thakur, Deshmukh and } \\
\text { Kaushik (2006) }\end{array}$} & \multirow{2}{*}{$\begin{array}{l}26 \text { Indian utilities responsible for } \\
\text { generation, distribution and transmission } \\
\text { of electricity. }\end{array}$} & $\begin{array}{l}\text { Model A: } \\
\text { (1) Total costs. }\end{array}$ & \multirow{2}{*}{ 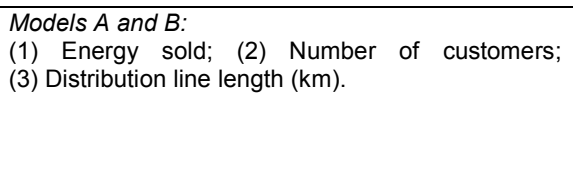 } & \\
\hline & & $\begin{array}{l}\text { Model B: } \\
\text { (1) Adjusted costs = total costs }- \text { salaries; (2) Number of } \\
\text { employees. }\end{array}$ & & \\
\hline \multirow{5}{*}{$\begin{array}{l}\text { von Hirschhausen, } \\
\text { Cullmann and Kappeler } \\
\text { (2006) }\end{array}$} & \multirow[t]{5}{*}{$\begin{array}{l}307 \text { German electricity distribution } \\
\text { utilities. }\end{array}$} & $\begin{array}{l}\text { Model } 1,2 \text { and } 7 \text { : } \\
\text { (1) Number of workers; (2) Length of electricity cables }(\mathrm{km}) \text {. }\end{array}$ & $\begin{array}{l}\text { Model 1: } \\
\text { (1) Units of energy sold; (2) Number of customers. }\end{array}$ & \\
\hline & & $\begin{array}{l}\text { Model 3: } \\
\text { (1) Number of workers; (2) Length of electricity cables (km); } \\
\text { (3) Peak load capacity (kw). }\end{array}$ & $\begin{array}{l}\text { Model 2, 3, 4, } 5 \text { and 6: } \\
\text { (1) Units of energy sold; (2) Number of customers; } \\
\text { (3) Inverse density index. }\end{array}$ & \\
\hline & & $\begin{array}{l}\text { Model 4: } \\
\text { (1) Number of workers; (2) Length of electricity cables (km); } \\
\text { (3) Turnover. }\end{array}$ & $\begin{array}{l}\text { Model 7: } \\
\text { (1) Units of energy sold; (2) Number of industrial } \\
\text { customers; (3) Number of households customers. }\end{array}$ & \\
\hline & & $\begin{array}{l}\text { Model 5: } \\
\text { (1) Number of workers; (2) Length of electricity cables (km); } \\
\text { (3) Electricity losses (Mwh). }\end{array}$ & & \\
\hline & & $\begin{array}{l}\text { Model 6: } \\
\text { (1) Number of workers; (2) Weighted sum of cable and } \\
\text { aerial grid. }\end{array}$ & & \\
\hline Hess and Cullmann (2007) & $\begin{array}{l}307 \text { German electricity distribution } \\
\text { companies. }\end{array}$ & $\begin{array}{l}\text { (1) Number of workers; (2) Weighted length of grid } \\
\text { (controlling for different voltage levels and aerial and cable } \\
\text { lines). }\end{array}$ & $\begin{array}{l}\text { (1) Total electricity delivered; (2) Number of } \\
\text { customers; (3) Inverse density index. }\end{array}$ & \\
\hline \multirow[t]{2}{*}{ Lins et al (2007) } & $\begin{array}{l}\text { Model 1: } 20 \text { power distribution companies } \\
\text { in Brazil. }\end{array}$ & $\begin{array}{l}\text { Model 1: } \\
\text { (1) Operational cost per employee; (2) \% power losses due } \\
\text { to interruptions. }\end{array}$ & $\begin{array}{l}\text { Model 1: } \\
\text { No outputs. }\end{array}$ & \\
\hline & $\begin{array}{l}\text { Model 2: } 18 \text { power distribution companies } \\
\text { in Brazil. }\end{array}$ & $\begin{array}{l}\text { Model 2: } \\
\text { (1) Operational costs; (2) N.o of employees; (3) \% power } \\
\text { losses due to interruptions; (4) N.o of interruptions (SAIDI); } \\
\text { (5) Hours of interruption (SAIFI); (6) Network size (km). }\end{array}$ & $\begin{array}{l}\text { Model 2: } \\
\text { (1) Number of customers; (2) Energy delivered; } \\
\text { (3) Service area }(\mathrm{km}) \text {. }\end{array}$ & \\
\hline
\end{tabular}




\begin{tabular}{|c|c|c|c|c|}
\hline Study & DMUs & Inputs & Outputs & Environmental Variables \\
\hline Arocena (2008) & 12 Spanish electrical utilities. & $\begin{array}{l}\text { Inputs for power distribution and supply: } \\
\text { (1) Total costs; (2) Installed Capacity Equivalent Interruption } \\
\text { Time. }\end{array}$ & $\begin{array}{l}\text { Outputs for power distribution and supply: } \\
\text { (1) Low voltage power distributed; (2) High voltage } \\
\text { power distributed; (3) Number of customers. }\end{array}$ & \\
\hline $\begin{array}{l}\text { Cullmann and von } \\
\text { Hirschhausen (2008a) }\end{array}$ & $\begin{array}{l}32 \text { Polish electricity distribution } \\
\text { companies. }\end{array}$ & (1) Number of workers; (2) Length of network (km). & $\begin{array}{l}\text { (1) Number of customers; (2) Electricity distributed; } \\
\text { (3) Inverse density index. }\end{array}$ & \\
\hline \multirow[t]{2}{*}{$\begin{array}{l}\text { Cullmann and von } \\
\text { Hirschhausen (2008b) }\end{array}$} & \multirow{2}{*}{$\begin{array}{l}84 \text { electricity distribution companies in } \\
\text { Poland, Czech Republic, Slovakia, } \\
\text { Hungary and German. }\end{array}$} & $\begin{array}{l}\text { Model 1: } \\
\text { (1) Number of workers; (2) Length of electricity grid (km). }\end{array}$ & $\begin{array}{l}\text { Model 1: } \\
\text { (1) Total electricity sales; (2) Number of customers. }\end{array}$ & \\
\hline & & $\begin{array}{l}\text { Model 2: } \\
\text { Same as Model } 1 .\end{array}$ & $\begin{array}{l}\text { Model 2: } \\
\text { (1) Total electricity sales; (2) Number of customers; } \\
\text { (3) Inverse density index. }\end{array}$ & \\
\hline $\begin{array}{l}\text { Estache, Tovar and Trujillo } \\
\text { (2008) }\end{array}$ & $\begin{array}{l}12 \text { operators providing services in } 12 \\
\text { countries members of the Southern } \\
\text { African Power Pool. }\end{array}$ & (1) Number of employees; (2) Installed capacity. & $\begin{array}{l}\text { (1) Number of customers; (2) Energy delivered; } \\
\text { (3) Energy generated. }\end{array}$ & \\
\hline Sadjadi and Omrani (2008) & 38 electricity distribution firms in Iran. & $\begin{array}{l}\text { (1) Number of employees; (2) Network length (km); } \\
\text { (3) Transformers capacity (MVA). }\end{array}$ & (1) Total electricity sales; (2) Number of customers. & \\
\hline Azadeh et al (2009a) & 38 electricity distribution units in Iran. & $\begin{array}{l}\text { (1) Network length; (2) Transformers capacity; (3) number of } \\
\text { employees. }\end{array}$ & (1) Number of customers; (2) Total electricity sales. & \\
\hline $\begin{array}{l}\text { Azadeh, Ghaderi and } \\
\text { Omrani (2009b) }\end{array}$ & 17 electricity distribution units in Iran. & $\begin{array}{l}\text { (1) Network length; (2) Transformers capacity; (3) Number } \\
\text { of employees. }\end{array}$ & (1) Units of electricity delivered (MWh). & \\
\hline \multirow[t]{2}{*}{$\begin{array}{l}\text { Pérez-Reyes and Tovar } \\
\text { (2009) }\end{array}$} & 14 distribution companies from Peru. & $\begin{array}{l}\text { Model 1: } \\
\begin{array}{ll} & \\
\text { (1) Number of employees; } & \text { (2) Network length; } \\
\text { (3) Distribution power losses; (4) Number of substations. }\end{array}\end{array}$ & $\begin{array}{l}\text { Models } 1 \text { and 2: } \\
\text { (1) Annual sales of electricity; (2) Number of } \\
\text { customers. }\end{array}$ & \\
\hline & & $\begin{array}{l}\text { Model 2: } \\
\text { (1) Number of employees; (2) Distribution power losses; } \\
\text { (3) Monetary value of active capital. }\end{array}$ & & \\
\hline Ramos-Real et al (2009) & 17 Brazilian electricity distribution utilities. & $\begin{array}{l}\text { (1) Number of employees; (2) Network length (km); } \\
\text { (3) Power lost due to interruptions. }\end{array}$ & (1) Energy delivered; (2) Number of customers. & (1) Service area. \\
\hline Tsutsui and Goto (2009) & $\begin{array}{l}90 \text { vertically integrated electric power } \\
\text { companies in the US. }\end{array}$ & $\begin{array}{l}\text { (1) Costs of the generation division; (2) Costs of the } \\
\text { transmission division; (3) Costs of the distribution division; } \\
\text { (4) Costs of the sales division; (5) Costs of the general } \\
\text { administrative division. }\end{array}$ & (1) Electric power sales to final customers. & \\
\hline $\begin{array}{l}\text { Yu, Jamasb and Pollitt } \\
\text { (2009) }\end{array}$ & $\begin{array}{l}12 \text { distribution networks in the United } \\
\text { Kingdom. }\end{array}$ & $\begin{array}{l}\text { (1) Customer minutes lost } \times \text { Number of customers; } \\
\text { (2) Operating expenditure; (3) Total expenditure. }\end{array}$ & $\begin{array}{l}\text { (1) Number of customers; (2) Units of energy } \\
\text { delivered. }\end{array}$ & \\
\hline
\end{tabular}




\section{REFERENCES}

Agrell PJ, Bogetoft P and Tind J (2005). DEA and Dynamic Yardstick Competition in Scandinavian Electricity Distribution. Journal of Productivity Analysis 23: 173-201.

Allen R, Athanassopoulos A, Dyson RG and Thanassoulis E (1997). Weight restrictions and value judgements in data envelopment analysis: evolution, development and future directions. Ann Opns Res 73: 13-34.

Arocena, P (2008). Cost and quality from diversification and vertical integration in electricity industry: A DEA approach. Energy Economics 30: 39-58.

Azadeh A, Ghaderi SF, Omrani H and Eivazy H (2009a). An integrated DEA-COLS-SFA algorithm for optimisation and policy making of electricity distribution units. Energy Policy 37: 2605-2618.

Azadeh A, Ghaderi SF and Omrani (2009b). A deterministic approach for performance assessment and optimization of power distribution units in Iran. Energy Policy 37: 274-280.

Bagdadioglu N, Price CW and Weyman-Jones TG (1996). Efficiency and ownership in electricity distribution: A nonparametric model of the Turkish experience. Energy Economics 18: 1-23.

Berg S, Lin C and Tsaplin V (2005). Regulation of State-Owned and Privatized Utilities: Ukraine Electricity Distribution Company Performance. Journal of Regulatory Economics 28 (3): 259-287.

Boussofiane A, Dyson RG and Thanassoulis E (1991). Applied data envelopment analysis. Eur J Op/ Res 52: 1-15.

Caves DW, Christensen LR and Diewert DE (1982). The Economic Theory of Index Numbers and the Measurement of Input, Output, and Productivity. Econometrica 50(November): 1393-1414.

Charnes A, Cooper WW, Divine D, Ruefli TW and Thomas D (1989). Comparisons of DEA and existing ratio and regression systems for effecting efficiency evaluations of regulated electric cooperatives in Texas. Research in Governmental and Nonprofit Accounting 5: 187-210.

Charnes A, Cooper WW and Rhodes E (1978). Measuring the efficiency of decision making unites. Eur J Opl Res 26(6): 429-444.

Chen T (2002). An assessment of technical efficiency and cross-efficiency in Taiwan's electricity distribution sector. Eur J Opl Res 137: 421-433.

Chien CF, Lo FY and Lin JT (2003). Using DEA to Measure the Relative Efficiency of the Service Center and Improve Operation Efficiency Through Reorganization. IEEE Transactions on Power Systems 18(1): 366373.

Cooper WW, Seiford L and Tone K (2000). Data Envelopment Analysis: A Comprehensive Text with Models, Applications, References and DEA-Solver Software. Kluwer Academic Publishers: Massachusetts.

Cooper WW, Seiford L and Zhu J (2004). Handbook on data envelopment analysis. Kluwer Academic Publishers: Massachusetts.

Cullmann A and von Hirschhausen C (2008a). From transition to competition Dynamic efficiency analysis of Polish electricity distribution companies. Economics of Transition 16 (2): 335-357.

Cullmann A and von Hirschhausen C (2008b). Efficiency analysis of East European electricity distribution in transition: legacy of the past? J Prod Anal 29: 155-167.

Dyson RG, Allen R, Camanho AS, Podinovski VV, Sarrico CS and Shale EA (2001). Pitfalls and protocols in DEA. Eur J Opl Res 132: 245-259.

Edvardsen DF and Førsund FR (2003). International benchmarking of electricity distribution utilities. Resource and Energy Economics 25: 353-371.

Estache A, Rossi MA and Ruzzier CA (2004). The Case for International Coordination of Electricity Regulation: Evidence from the Measurement of Efficiency in South America. Journal of Regulatory Economics 25 (3): 271-295. 
Estache A, Tovar B and Trujillo L (2008). How efficient are African electricity companies? Evidence from the Southern African Countries. Energy Policy 36: 1969-1979.

Färe R, Grosskopf S, Lindgren B and Roos P $(1989,1994)$. Productivity change in Swedish hospitals: a Malmquist output index approach. In: Charnes A, Cooper WW, Lewin AY and Seiford ML (eds). Data Envelopment Analysis: Theory, Methodology and Applications. Kluwer Academic Publishers: Boston, pp 253-272.

Färe R, Grosskopf S and Logan J (1983). The relative efficiency of Illinois electric utilities. Resources and Energy 5(4): 349-367.

Førsund FR and Kittelsen SC (1998). Productivity development of Norwegian electricity distribution utilities. Resource and Energy Economics 20: 207-224.

Giannakis D, Jamasb T and Pollitt M (2005). Benchmarking and incentive regulation of quality of service: an application to the UK electricity distribution networks. Energy Policy 33: 2256-2271.

Golany B and Roll Y (1993). Some extensions of techniques to handle non-discretionary factors in data envelopment analysis. Journal of Productivity Analysis 4(4): 419-432.

Haney AB and Pollitt MG (2009). Efficiency analysis of energy networks: An international survey of regulators. Energy Policy 37: 5814-5830.

Hattori T, Jamasb T and Pollitt M (2005). Electricity Distribution in the UK and Japan: A Comparative Efficiency Analysis 1985-1998. The Energy Journal 26(2): 23-47.

Hess B and Cullmann A (2007). Efficiency analysis of East and West German electricity distribution companies - Do the "Ossis" really beat the "Wessis"? Utilities Policy 15: 206-214.

Hjalmarsson L and Veiderpass A (1992). Efficiency and ownership in Swedish electricity retail distribution. Journal of Productivity Analysis 3: 7-23.

Jamasb T and Pollitt M (2003). International benchmarking and regulation: an application to European electricity distribution utilities. Energy Policy 31: 1609-1622.

Korhonen P and Syrjänen MJ (2003). Evaluation of Cost Efficiency in Finnish Electricity Distribution. Ann Opns Res 121: 105-122.

Kumbhakar SC and Hjalmarsson L (1998). Relative performance of public and private ownership under yardstick competition: electricity retail distribution. European Economic Review 42: 97-122.

Lins MPE, Sollero MKV, Calôba GM and Silva ACM (2007). Integrating the regulatory and utility firm perspectives, when measuring the efficiency of electricity distribution. Eur J Opl Res 181: 1413-1424.

Lo FY, Chien CF and Lin JT (2001). A DEA study to evaluate the relative efficiency and investigate the district reorganization of the Taiwan power company. IEEE Transactions on Power Systems 16: 170-178.

Malmquist S (1953). Index Numbers and Indifference Surfaces. Trabajos de Estadistica 4: 209-242.

Miliotis PA (1992). Data envelopment analysis applied to electricity distribution districts. J Op/ Res Soc 43(5): 549-555.

Pacudan R and de Guzman E (2002). Impact of energy efficiency policy to productive efficiency of electricity distribution industry in the Philippines. Energy Economics 24: 41-54.

Pahwa A, Feng X and Lubkerman D (2002). Performance Evaluation of Electric Distribution Utilities Based on Data Envelopment Analysis. IEEE Transactions on Power Systems 17(3): 400-405.

Pardina MA, Rossi MA and Ruzzier CA (1998). Fronteras de eficiencia en el sector de distribución de energía eléctrica: la experiencia sudamericana. Anais do XX Encontro Brasileiro de Econometria II, 381-400.

Pérez-Reyes R and Tovar B (2009). Measuring efficiency and productivity change (PTF) in the Peruvian electricity distribution companies after reforms. Energy Policy 37: 2249-2261.

Podinovski VV (2004). Production trade-offs and weight restrictions in data envelopment analysis. J Op/ Res Soc 55: 1311-1322. 
Podinovski VV (2005). The explicit role of weight bounds in models of data envelopment analysis. J Op/ Res Soc 56: 1408-1418.

Podinovski VV (2006). Improving data envelopment analysis by the use of production trade-offs. J Op/ Res Soc 58: 1261-1270.

Pollitt M (1995). Ownership and Performance in Electric Utilities: the International Evidence on Privatisation and Efficiency. Oxford University Press: Oxford.

Pollitt M (2005). The role of efficiency estimates in regulatory price reviews: Ofgem's approach to benchmarking electricity networks. Utilities Policy 13: 279-288.

Pombo C and Taborda R (2006). Performance and efficiency in Colombia's power distribution system: Effects of the 1994 reform. Energy Economics 28: 339-369.

Ramos-Real FJ, Tovar B, lootty M, Almeida EF and Pinto Jr. HQ (2009). The evolution and main determinants of productivity in Brazilian electricity distribution 1998-2005: An empirical analysis. Energy Economics 31: 298-305.

Resende M (2002). Relative efficiency measurement and prospects for yardstick competition in Brazilian electricity distribution. Energy Policy 30: 637-647.

Sadjadi SJ and Omrani H (2008). Data envelopment analysis with uncertain data: An application for Iranian distribution companies. Energy Policy 36: 4247-4254.

Sanhueza R, Rudnick H and Lagunas H (2004). DEA Efficiency for the Determination of the Electric Power Distribution Added Value. IEEE Transactions on Power Systems 19(2): 919-925.

Scriven M (1967). The methodology of evaluation, in Tyler RW, Gagne RM and Scriven M (eds), Perspectives on Curriculum Evaluation, Chicago: Rand McNally, pp. 39-83.

Tanure JEPS, Tahan CMV and Lima JWM (2006). Establishing quality performance of distribution companies based on yardstick regulation. IEEE Transactions on Power Systems 21 (3): 1148-1153.

Thakur T, Deshmukh SG and Kaushik SC (2006). Efficiency evaluation of the state owned electric utilities in India. Energy Policy 34: 2788-2804.

Tone K (2001). A slack-based measure of efficiency in DEA. Eur J Opl Res 130: 498-509.

Tone K (2004). Malmquist Productivity Index: Efficiency Change Over Time. In: Cooper WW, Seiford LM and Zhu J (eds). Handbook on Data Envelopment Analysis. Kluwer Academic Publishers: London, pp 203227.

Tsutsui M and Goto M (2009). A multi-division efficiency evaluation of US electric power companies using a weighted slacks-based measure. Socio-Economic Planning Sciences 43: 201-208.

Von Hirschhausen C, Cullmann A and Kappeler A (2006). Efficiency analysis of German electricity distribution utilities - non-parametric and parametric tests. Applied Economics 38: 2553-2566.

Weyman-Jones TG (1991). Productive efficiency in a regulated industry: the area electricity boards of England and Wales. Energy Economics April: 116-122.

Weyman-Jones TG (1995). Problems of yardstick regulation in electricity distribution. In: Bishop M, Kay J and Mayer C (eds). The Regulatory Challenge. Oxford University Press: Oxford, pp 423-443.

Weyman-Jones TG, Boucinha J and Inácio CF (2008). Efficiency Analysis of Maintenance and Outage Repair in Electricity Distribution. Portuguese Journal of Management Studies XIII: 89-110.

Weyman-Jones TG, Boucinha J, Inácio CF, Godinho C and P Martins (2004). Slacks Based Efficiency Measurement: an application to electricity networks. 4th International Symposium on DEA. Aston University.

Wholey JS (1996). Formative and Summative Evaluatuion: Related Issues in Performance Measurement. Evaluation Practice 17 (2): 145-149. 
Yang C and Lu WM (2006). Assessing the Performance and Finding the Benchmarks of the Electricity Distribution Districts of Taiwan Power Company. IEEE Transactions on Power Systems 21(2): 853-861.

Yu W, Jamasb T and Pollitt M (2009). Does weather explain cost and quality performance? An analysis of UK electricity distribution companies. Energy Policy 37: 4177-4188.

Zhang $Y$ and Bartels $R$ (1998). The effects of sample size on the mean efficiency in DEA with an application to electricity distribution in Australia, Sweden and New Zealand. Journal of Productivity Analysis 9: 187-204. 